\title{
Severe and enduring somatoform disorders: recognition and management
}

\author{
Christopher Bass \& Steve Pearce
}

\begin{abstract}
SUMMARY
Patients with severe and enduring somatoform disorders (SESD) characteristically present with multiple, recurrent and frequently changing physical symptoms that have usually been present for several years before referral to a psychiatrist/ psychologist. Many patients report long histories of contact with both primary and tertiary care services, have undergone repeated fruitless investigations and have high levels of disability. SESD are responsible for disproportionately high healthcare costs and are the third most common cause of workplace absence. Identification of patients with SESD by psychiatrists requires particular skills: collaboration with colleagues is vital and there are risks of iatrogenic harm. We describe the obstacles encountered in identifying these patients as well as methods of assessment and management. Treatment pathways best suited to managing this large and as yet untended group of patients are described.
\end{abstract}

\section{LEARNING OBJECTIVES}

- Learn to identify patients with SESD and explore the key role of a developmental illness history or time line

- Be able to assess both the physical and psychological state of patients with SESD and to identify the risk factors for chronicity

- Be able to plan a management programme and be aware of the resources available in diverse treatment settings

\section{DECLARATION OF INTEREST}

None

In an earlier BJPsych Advances article, Robinson (2014) introduced the term severe and enduring eating disorders (SEED) to describe patients with severe eating disorders that required the regular attention of a multidisciplinary team. Here we describe another neglected group of patients who are more usually encountered in primary care and general hospital settings and account for disproportionately high healthcare costs (Anderson 2013). These patients have severe and enduring somatoform disorders (SESD) (Box 1) and report multiple, diverse physical symptoms over a prolonged period (for the sake of this review

\section{BOX 1 Definition of somatoform disorders}

Somatoform disorders are defined in ICD-10 as 'repeated presentation of physical symptoms over a number of years, together with persistent requests for medical investigations, in spite of repeated negative findings and reassurances by doctors that the symptoms have no physical basis' (World Health Organization 1992). In DSM-5 it is acknowledged that the symptoms may or may not be associated with another medical condition (American Psychiatric Association 2013).

5 or more years), with no relevant organic disease to account for their symptoms, although they may have coexisting medical disorders (Boxes 2 and 3). ${ }^{\text {a }}$ The key word here is relevant.

These patients are often not accepted into psychiatric care because they do not have 'severe and enduring mental illness' (SEMI) (Department of Health 1999). However, it has been repeatedly shown that they have significant disabilities, comparable to those seen in severe mental illnesses such as schizophrenia and chronic depression (Kushwaha 2014; Rask 2015), and that they also make extraordinary demands on carers

BOX 2 Somatoform disorder and disability

A man of 50 was referred to the psychiatric out-patient clinic from his occupational health doctor with symptoms of panic attacks, abdominal pains and tremors of both upper limbs. He was finding it difficult to work as a council gardener because he was convinced that his line manager was talking about him behind his back. He was distressed by his physical sensations and, because of his tremors, he could not use his tools. Examination of his medical records revealed a long history of recurrent physical symptoms such as fatigue, tremors, facial and abdominal pains occurring at times of life stress, usually involving interpersonal problems at work. He had been seen by a psychiatric service in his 20s, when he was diagnosed with dependent, paranoid and avoidant personality traits, and had received drug treatment and marital therapy. His complaints of multiple recurrent physical symptoms had occurred since adolescence and had led to significant use of medical resources and lifetime sickness absence.
Christopher Bass is a consultant in liaison psychiatry at the John Radcliffe Hospital, Oxford. Steve Pearce is a consultant in psychiatry at Oxford Health Complex Needs Service. Correspondence Dr Christopher Bass, Department of Psychologica Medicine, John Radcliffe Hospital, Oxford OX3 9DU, UK. Email: christopher.bass@oxfordhealth. nhs.uk

a. Details in the case vignettes in this article have been altered to protect patients' privacy. 
B0X 3 Chronic physical illness coexisting with somatoform disorder

A 45-year-old man with mild rheumatoid arthritis but with normal inflammatory markers reported a variety of diverse somatic complaints unrelated to his joints, including abdominal pain, headaches and fatigue. He was extremely introspective and worried excessively about his health and had consulted his general practitioner over 20 times in the previous year. His score on the PHQ- 15 was grossly elevated at $25 / 30$ and he was functionally impaired, becoming unable to work as a library assistant. He had been retired on medical grounds because of fibromyalgia. He satisfied diagnostic criteria for a persistent somatoform disorder (which had not been treated) coexisting with an (albeit mild) chronic medical disorder, rheumatoid arthritis

(Krishnan 2013). SESD continue to be neglected by both psychiatric and medical services. The main reasons, in our opinion, are shown in Box 4.

\section{Definitions}

The term somatoform disorder has been replaced in DSM-5 by somatic symptom disorder (American Psychiatric Association 2013), which represents a 'consolidation of previously listed diagnoses' (Dimsdale 2013). We will retain the former generic term in this article because most psychiatrists are familiar with it, many physicians are aware of it and use it, and much of the research cited below in this review has been based on DSM-IV criteria (American Psychiatric Association 1994).

There have been two major changes from DSMIV worth emphasising. First, DSM-5 recognises that somatoform disorders can be associated with another medical condition, and that excessive reliance on medically unexplained symptoms

\section{BOX 4 Reasons why SESD are neglected}

- The 'firewall' that continues to exist between medical and psychiatric services is not merely geographical - it is often initiated at an early stage in medical education

- Many physicians are not trained to recognise or identify patients with concurrent physical and psychiatric disorders

- Clinicians generally (for pragmatic reasons) tend to adopt a cross-sectional rather than a developmental or life-course approach (one reason for this is that patients' notes in modern out-patient clinics rarely include the complete medical record or illness history)

- 'Somatic attribution' of symptoms is often a feature of these patients, who may avoid acknowledging psychosocial problems

- Primary care doctors do not always respond to psychosocial cues, which leads to the avoidance of psychiatric services

- Medical journals rarely contain narrative accounts of patients' illnesses

- There is confusion in the literature about the classification of functional syndromes
(MUS) is simplistic and reinforces mind-body dualism (Sharpe 2013). Second, it proposes that central to these disorders are distressing thoughts, feelings and behaviours and that health concerns are often paramount and occasionally preoccupying (Rief 2010; Riebel 2013). These key characteristics are more 'psychological' and will be described later.

One unfortunate feature of this area of medical practice is that most physicians are uncomfortable with psychiatric nosology, often preferring to use terms such as chronic fatigue syndrome, fibromyalgia, irritable bowel syndrome and chronic pelvic pain. Psychiatrists working in this field need to be aware that (a) there is a considerable degree of overlap in the phenomenology of these so-called functional disorders (Kanaan 2007), and (b) there has been a recent acknowledgement by rheumatologists that fibromyalgia is a dimensional or continuum disorder (Wolfe 2013) that shares common characteristics with somatic symptom disorder (DSM-5). Indeed, $40 \%$ of people with fibromyalgia in the general population satisfy DSM-5 criteria for somatic symptom disorder, supporting the view that there is considerable overlap between these disorders.

In this article we will demonstrate that SESD are more widespread than is commonly acknowledged and that patients with SESD require the attention of a number of professionals from a wide variety of disciplines whose efforts need to be coordinated and documented.

\section{Indices of severity}

Not all patients with somatoform disorders fall into the SEMI category. In a systematic review of course and prognosis in patients with MUS, 10-30\% were shown to deteriorate (olde Hartman 2009). The key problem lies in identifying which patients will develop chronic symptoms and disabilities.

Severity is difficult to quantify but measures of service use, functional impairment and incapacity for work are useful proxy measures, as are high costs (Barsky 2005). In a recent 10-year follow-up study in primary care, Rask et al (2015) found that of patients with a DSM-IV persistent somatoform disorder, a fifth were in receipt of disability benefits and had an increased risk of sick leave compared with controls with a well-defined physical disease. In line with previous studies, many of the patients had chronic illnesses and high psychiatric comorbidity.

Another index of severity that can be easily measured in the clinic is the symptom burden or load, which can be documented with a brief rating scale, the PHQ-15 (Kroenke 2002). In a 
population-based study both somatic symptom burden and high health anxiety had important effects on functional impairment and healthcare use (Lee 2015). This suggests that the presence of both psychological features (criterion B under somatic symptom disorder in DSM-5) and bothersome symptoms describes a group with greater impairments (Tomenson 2013). Useful indices of illness severity include the following:

- number of physical symptoms or symptom load - as measured on the PHQ-15 (cut-off scores of 5, 10 and 15 represent low, medium and high somatic symptom load) (Kroenke 2002); it is important to note that self-rated symptom counts should not be used to identify patients with MUS (Carson 2015)

- use of primary care services (e.g. symptoms lasting at least 3 months and leading to loss of function) (Aamland 2014)

- use of secondary care services (e.g. the top $5 \%$ of out-patient attenders by number of appointments (Reid 2002)

- number of investigations/tests with negative outcome over a 24 -month period.

\section{IIIness duration}

One landmark study of illness longevity was conducted over 8 years (Fink 1992a), but overall there are few follow-up studies of patients with SESD. In previous longitudinal studies of patients who meet the criteria for somatoform disorders, between 22 and 53\% still have the disorder at follow-up (Jackson 2008; Steinbrecher 2011a). The same is true for patients with hypochondriasis (olde Hartman 2009).

It is important for clinicians to be aware of the chronic remittent nature of SESD. Indeed, there is increasing evidence that so-called functional somatic syndromes are linked through a polysyndromic phenotype (Warren 2014) and that patients with somatoform disorders often have extensive histories of functional syndromes such as fibromyalgia and irritable bowel syndrome.

\section{Disorder persistence}

The key issue for the clinician is to know what predicts persistence. Factors predicting severity are germane: there is evidence that the number of somatic symptoms at baseline and high health anxiety influence the course of these conditions (Jackson 2005), as do illness perceptions. Recent findings, however, have challenged the view that physical illness attributions are a key component of somatoform disorders. Frostholm et al (2015) concluded that it was important to distinguish between attribution of symptoms on the one hand (which may vary more in somatoform disorders than previously assumed) and cognitive characteristics such as catastrophising and negative illness perceptions (which have been shown to predict disability) on the other (Rief 2004, 2007). In disorders such as chronic fatigue syndrome, fibromyalgia and chronic whiplash, however, where the patient's views may be shaped by patient organisations and the internet, evidence suggests that illness beliefs and expectations for recovery can have a marked effect on outcome (Carroll 2011; Petrie 2012).

These findings are consistent with clinical experience that suggests that a combination of (a) the number of physical symptoms or symptom burden, as well as (b) illness beliefs and perceptions are key predictors of chronicity, as measured by poor outcome and high healthcare costs (Frostholm 2014).

\section{Coexisting personality disorder}

Another key predictor of chronicity is a coexisting personality disorder (Bornstein 2008) (Table 1). It has recently been shown that patients with borderline personality disorder are more likely to experience pain and rate their pain as more severe than patients with other personality disorders (Biskin 2014).

Personality disorder is underdiagnosed in routine clinical practice (Tyrer 2015a) and diagnostic accuracy is low, particularly in primary care. To achieve more than an indicative diagnosis, a semistructured interview is necessary, ideally involving informants and two or more meetings. Patient questionnaires tend to show low agreement with semi-structured interviews (Fossati 1998) and are best avoided. The most widely used diagnostic instrument is the Structured Clinical Interview for DSM-IV Axis II Disorders, the SCID-II (Gibbon 1997), which takes $1-2 \mathrm{~h}$ to administer and is based on the DSM-IV personality disorder criteria,

\section{TABLE 1 Personality disorders theoretically linked with SESD}

\begin{tabular}{|ll|}
\hline Category & Hypothesised underlying processes \\
\hline Antisocial & Reports of somatic symptoms may represent a form of malingering \\
\hline Avoidant & Somatic symptoms stem in part from unexpressed negative emotions \\
\hline Borderline & $\begin{array}{l}\text { Somatic symptoms reflect primitive defences used to modulate anxiety; } \\
\text { somatic defences may result from childhood adversity/abuse }\end{array}$ \\
\hline Dependent & $\begin{array}{l}\text { Somatic symptoms solicit nurturing responses from significant others and } \\
\text { enable the dependent person to develop relationships with caregivers/doctors }\end{array}$ \\
\hline Histrionic & \begin{tabular}{l} 
Somatic symptoms represent attention- and support-seeking behaviours \\
\hline $\begin{array}{l}\text { Obsessive- } \\
\text { compulsive }\end{array}$
\end{tabular} $\begin{array}{l}\text { Ruminations may lead to the interpretation of minor physical changes as } \\
\text { significant somatic symptoms (overlap here with some patients on the autism } \\
\text { spectrum) }\end{array}$ \\
\hline
\end{tabular}

Adapted with permission from Bornstein \& Gold (2008). 
which are unchanged in DSM-5. The equivalent ICD-10 semi-structured patient interview is the International Personality Disorder Examination (IPDE) (Loranger 1997), which is slightly longer. Assessments made on a single meeting, and without documentary evidence of former behaviour and difficulties or information from a third party who has known the patient over some time, are likely to be unreliable, and this may explain the reluctance of some clinicians to make the diagnosis (Paris 2007).

Personality disorder diagnostic criteria and categories will change substantially in ICD-11, which will introduce a tiered approach to personality dysfunction. It will comprise personality difficulty, which is likely to include the majority of the population, and mild, moderate and severe personality disorders, with qualifiers to indicate the domains within which the difficulties lie (e.g. negative affective, dissocial, anankastic, and detached) (Tyrer 2015a).

\section{Symptom substitution}

The vignette in Box 5 illustrates that when functional disability reflects unacknowledged psychological distress, results of improvement can have unpredictable psychiatric consequences. Conversely, suicidality and distress can reduce once disability has become established in a patient with SESD (Allanson 2002).

\section{Litigation}

Litigation is another predictor of chronicity. There is good evidence that those involved in litigation for financial rewards to compensate pain and suffering after traffic injury do not recover as quickly as those that have similar injuries and are not litigating (Cassidy 2011).

\section{Prevalence: how many SESD are out there?}

The prevalence of somatic symptom disorders in the general population has been estimated to be 5-7\% (Creed 2011).

\section{BOX 5 Symptom substitution}

A middle-aged woman presented to neurologists with loss of use of her legs. She had a history of functional illnesses. She was admitted for investigation, and when no cause was found a psychiatric consultation was arranged. She responded to brief exploratory treatment and, with physiotherapy, regained the use of her legs. Shortly after discharge she became acutely suicidal and began to self-harm severely. She was admitted to a psychiatric hospital for a prolonged period in an attempt to address her risk. A personality disorder was diagnosed.
In primary care settings the use of different measures and different samples leads to considerable variation in prevalence rates but most studies indicate an overall prevalence of 8-22\% (Creed 2011; Steinbrecher 2011b). Persistent somatoform pain disorder is not considered separately from somatoform disorder as the epidemiology is similar (Frohlich 2006).

Among patients attending a neurology clinic with more severe MUS, persistence over a year occurred in two-thirds and this was associated with the patient's belief that they would not improve, a failure to attribute the symptoms to a psychological cause and the receipt of illnessrelated financial benefits (Sharpe 2010).

\section{Clinical features}

In a Danish National Patient Register study, Fink (1992a) identified patients who, over an 8-year period, had been admitted repeatedly to hospital at least ten times for physical symptoms without an organic basis. He found that $84 \%$ were women and three-quarters were under 25 years old at the onset of the disorder. A third had 'hospital careers' of more than 20 years and accounted for $3 \%$ of the general population's admission to non-psychiatric hospitals. Most patients with somatoform disorders have chronic symptoms and high levels of disability (Bass 1991), and a high proportion have a coexisting medical disorder (Boxes 2 and 3). Coexisting medical and personality disorders may be associated with complex somatoform disorders, and in these cases assessment can be extremely difficult (Frankenberg 2004). Features that may alert the clinician are shown in Box 6.

\section{Psychological features}

There is evidence that the onset of SESD is associated with both physical (e.g. muscle trauma) and psychological (e.g. bereavement) triggers that initiate pain amplification and psychological distress (Holliday 2011). Psychological features likely to be characteristic of somatoform disorders are shown in Box 7.

\section{Personality disorder}

Numerous studies have reported that about threequarters of patients with somatoform disorders have a coexisting personality disorder. The highest prevalence rates occurred for antisocial, borderline, histrionic and dependent personalities, each of which was diagnosed in around $25 \%$ of patients with somatoform disorder (Bornstein 2008) (Table 1). Tyrer et al (1990) identified $2.5 \%$ of psychiatric patients sharing stable characteristics of an excessive preoccupation with the maintenance of 
BOX 6 Clinical characteristics that may alert the clinician to SESD

- History of pain-related surgery, especially for similar pains (DeVaul 1980)

- Polysyndromic phenotype, i.e. repeated presentations of functional disorders throughout the life cycle for 5 years or more (Warren 2013)

- Belief/expectations that the symptoms will not improve (Carroll 2011)

- Failure to attribute symptoms to a psychosocial cause, i.e. a somatic attributional style despite evidence to the contrary (Frostholm 2014)

- In receipt of illness-related financial benefits (Sharpe 2010)

- High levels of health anxiety (Lee 2015)

- High number of somatic symptoms or high symptom burden (Lee 2015)

- Feeling of lack of control over symptoms (Petrie 2012)

- Coexisting personality disorder (Frankenburg 2004; Bornstein 2008)

- Involvement in prolonged litigation related to symptoms (Cassidy 2011)

health, a tendency to overattend to minor physical symptoms and frequent medical consultations. A follow-up study provided support for the poor prognosis in patients with a hypochondriacal personality disorder (Tyrer 1999).

\section{Childhood adversity}

Childhood adversity, including neglect and abuse, has been identified as another risk factor for frequent attending in primary care (Kapur 2004) and at medical out-patient departments in general hospitals (Fiddler 2004) and for somatoform disorders in adult life (Borsini 2014). However, childhood adversity is a risk factor for a variety of adverse physical and mental health outcomes in adult life (Arnow 2004).

\section{Costs}

It has been well established that patients with SESD use extraordinary amounts of healthcare resources, in both direct costs (e.g. out-patient physician visits) and indirect costs (e.g. early retirement and sickness absence) (Konnopka 2013). In the UK, Kinder et al (2006) reported a patient with a somatoform disorder whose costs to the National Health Service (NHS) were $£ 209000$ in 2004 (not taking into account other potential costs such as primary care consultations, accident and emergency department visits, and attendances at other hospitals). It has also been shown that patients with MUS referred repeatedly
BOX 7 Psychological and behavioural characteristics likely to be important in patients with SESD
- Health anxiety (i.e. ruminating about bodily symptoms)

- Catastrophic thinking (e.g. these

- Self-concept of bodily weakness

- Intolerance of bodily complaints

- Avoidance of activity that could raise heart rate or aggravate bodily complaints palpitations are causing damage)
- Disuse of a limb, especially if painful

- Pain behaviour (e.g. unprescribed wheelchair use)

- Somatic illness attribution despite contradictory medical information (e.g. attributing multiple diverse symptoms to a physical cause such as lead poisoning, rather than to stressful work situations)

(Rief 2010; Voigt 2013) to secondary care incur healthcare costs similar to those whose symptoms are explained by somatic disease (Burton 2012a; Andersen 2013).

\section{latrogenesis and somatoform disorders}

Patients with somatoform disorders are particularly likely to be subject to iatrogenic harm. There are many explanations for this. One reason is that they often misinterpret remarks/comments about their physical complaints, so that a reassuring comment from a neurologist that 'We can't find anything seriously wrong on the scans' is transformed in the patient's mind to 'That's because you haven't looked hard enough' or 'You didn't find anything on the scan because I didn't have the headache on that day'. This may lead to seeking out further unnecessary tests. Other sources of iatrogenic harm derive from unwanted drug side-effects (e.g. morphine derivatives causing constipation) and inappropriate labelling of symptoms, for example ascribing a painful limb to complex regional pain syndrome when there is insufficient evidence to support this diagnosis and then arranging for an invasive treatment that leads to infection (Kouyanou 1997).

In our clinical experience there are a number of rare medical syndromes that have high rates of coexisting functional disorders and use of opiates (often with unrecorded antecedent medical and psychiatric histories). Many of these patients bear a strong similarity to the polysyndromic phenotype described by Warren et al (2014). These patients need to be screened for chronic somatoform disorders (Box 8).

The most serious iatrogenic complication is unnecessary surgery. Among women with interstitial cystitis or bladder pain, the number of previous functional syndromes such as fibromyalgia or irritable bowel syndrome was strongly correlated with the number of surgeries. This suggests that care should be taken before offering surgery to patients with a 'polysyndromic phenotype', 
BOX 8 Rare medical syndromes that share common characteristics with SESD

- Sphincter of Oddi dysfunction type 3 (Abraham 1997)

- Idiopathic slow-transit colon (Dykes 2001)

- Loin pain haematuria syndrome (Vakili 2014)

- Complex regional pain syndrome type 1 (Vranceanu 2011)

- Fowler's syndrome (Hoeritzauer 2015)

characterised by repeated presentations of functional disorders over a long period of time (Warren 2014) (Box 9).

\section{Identification: methods of assessment}

It is clear from research findings that SESD often go unrecognised. The main reason for this is that patients often pursue their 'illness journeys' in non-psychiatric healthcare settings such as general hospital out-patient clinics. Another is that interviewing these patients is beset with difficulties. First, medical notes are not always available at the assessment interview; second, reported previous diagnoses by these patients (especially those with neurological symptoms) are often unreliable, especially if the list of previous diagnoses is particularly long (Schrag 2004); and third, time is often restricted and does not allow for the collection of data from informants.

\section{Electronic medical records}

Recent use of electronic medical records to detect these patients in primary care has shown promise, and frequent attenders at out-patient clinics can be identified using computerised records (den Boeft 2014). Early detection in primary care would allow the general practitioner (GP) to engage with the patient proactively and develop a practical management plan. There is an urgent need to carry out more studies using this technology.

BOX 9 Polysyndromic patient with multiple somatic syndromes

A 37-year-old woman was seen in the pain clinic with fibromyalgia or chronic widespread pain. She complained of pain all over her body since straining her left knee 2 years previously and was confined to a wheelchair and had an indwelling catheter. Her schooling had been interrupted by chronic abdominal pain and headaches and there was a history of childhood neglect with recurrent episodes of depression and self-harm. She had also suffered from irritable bowel syndrome, temporomandibular joint pains and urinary frequency since her mid-20s and had had dyspareunia and menorrhagia, leading to hysterectomy at the age of 29. Episodes of illness had led to frequent absences from work. All investigations (including bladder studies) were normal. She was being investigated for Fowler's syndrome, had a carer and was in receipt of disability-related financial support.

\section{Documenting a chronology}

Because of the constitutional nature of SESD (Bass 1995) we recommend the adoption of a developmental or life-course approach. This involves collecting all previous medical notes from both primary and secondary care and documenting a chronology such as the example in online Table DS1. This should be placed in the medical file.

\section{Awareness among medical students}

Identification would also be improved by increasing medical students' awareness of SESD. Medical students are currently taught medicine and psychiatry as if they are separate disciplines; this 'firewall' does not reflect clinical realities and perpetuates the mind-body split that permeates our healthcare system (Box 4). Attitudes to teaching about somatoform disorders require a major shift, and should involve a role for both psychologists and primary care physicians, because it is incumbent on doctors in primary care (as well as specialist physicians) to identify patients with MUS at an earlier stage in the evolution of their illness, before secondary handicaps develop.

\section{Problems in children}

Up to half of paediatric primary care visits are for MUS (van Ravesteijn 2009). A study of 161 patients admitted to a paediatric ward with diagnosed somatoform disorder revealed that the mean age was 14.4 years and $75 \%$ were female (Bujoreanu 2014). The most common physical symptoms were pain (58\%) and neurological symptoms (40\%); 73\% had a medical diagnosis and two-thirds a history of psychiatric treatment. Children with histories of trauma had significantly higher rates of psychiatric comorbidities and parental mental illness and were more likely to require in-patient psychiatric treatment on discharge (Thomsen 2014). Associations between consultation behaviour for MUS in children and parents has become a recent focus of investigation (Shraim 2014).

\section{Management}

\section{Where should it take place?}

Addressing MUS is a priority for NHS England, and current plans involve delivering treatment via the Improving Access to Psychological Therapies (IAPT) programme (Improving Access to Psychological Therapies 2015). Recent emphasis has focused on the location of care. A number of initiatives have been introduced, including a symptom management clinic located within primary care (Burton 2012b; Röhricht 2014). 
Patients with complex somatoform disorders can be identified in primary care settings, where the involvement of the GP is considered crucial. A short feedback session with both GP and patient following the clinic helps to develop a collaborative approach to ongoing management. Early identification is important, as once SESD have become established, outcomes are poor.

\section{What treatments are effective?}

Because patients with SESD frequently use healthcare resources in a variety of settings, a key question about management involves not only where treatment is to take place, but also what type is offered and by whom.

\section{Non-pharmacological interventions}

A recent Cochrane review of non-pharmacological interventions for somatoform disorders (van Dessel 2014) concluded that, compared with enhanced or structured care, psychological therapies showed no advantage but were generally superior to usual care or waiting list in terms of reduction in symptom severity, although effect sizes were small. Compared with enhanced care, cognitivebehavioural therapy (CBT) was not more effective. The authors drew attention to the fact that a substantial proportion of participants were not willing to accept psychological treatments.

A recent study of health anxiety in medical patients showed that a modified form of CBT was effective, and furthermore that those patients treated by non-mental health staff had better outcomes than those treated by other professional groups (Tyrer 2015b).

Current evidence does not answer the question whether enhanced care delivered by primary care professionals has an effect on outcome. It may have an impact when delivered per protocol to well-defined groups of patients with functional disorders, but more intensive interventions are likely to be more successful in changing patient outcomes (Rosendal 2013).

\section{Tailored treatments}

Because of the heterogeneity among patients with SESD (which overlap with patients with conversion disorder or functional neurological symptom disorder), treatments may have to be tailored to the type of clinical presentation (Box 10). For example, a patient with functional weakness in a wheelchair may require a different approach from a frequent attender at a gastroenterology clinic with multiple diverse symptoms. This key point needs to be considered in designing intervention studies for patients with SESD (Stone 2014).
BOX 10 Overcoming psychosocial obstacles to recovery in SESD
A 19-year-old woman was referred by the neurology service with functional weakness in both legs and was confined to a wheelchair at home. Her house had been adapted and because of her immobility a home visit was organised. Although she initial assessment (apart from a history of severe irritable bowel syndrome) she agreed to be admitted to the neurology rehabilitation unit for further assessment. During this admission she revealed that denied any psychosocial problems at the her father was physically beating her and she had 'retreated' to her wheelchair to avoid further abuse (i.e. adopted an invalid role). This was discussed at a family meeting, after which her father left home and abandoned the family. This created a favourable environment for her to respond to both physiotherapy and psychological support. Following discharge she was well enough to pass her driving test, enrol in a local college and move to another city with her new partner.
There are useful websites for people with functional neurological disorders (e.g. www. neurosymptoms.org and www.nonepilepticattacks. info), and both patients and carers might benefit from them.

\section{Service delivery and care management}

It is clear that more research is needed to identify suitable service delivery pathways and type of service delivery that would provide adequate care for patients with SESD. A Dutch study proposed a stepped-care model for high-risk patients with chronic somatoform disorders and a problematic relationship with their GP: specialist multidisciplinary mental healthcare in a psychiatric setting with case management is recommended for this group (van der Feltz-Cornelis 2012). For more severe cases (e.g. patients confined to bed or a wheelchair), in-patient treatment may be required (Box 10). It is promising to note that commissioners have recognised that resources need to be assigned to this large, neglected and costly patient group (Anderson 2013).

We therefore suggest the following approach to care management for SESD, consistent with the care programme approach:

- regular monitoring of coexisting medical disorders

- a multidisciplinary management plan reviewed every 6 months, possibly involving specialist (tier 3) personality disorder services (if personality disorder is present) and/or medical specialists

- regular review of any benefits received (e.g. disability-related financial support and health aids); this may require liaison with community physiotherapists, occupational therapists, etc.

\section{Management informed by attachment theory and disorders of early attachment}

It has been shown that individuals with insecure adult attachment styles not only report more pain 
than those with secure attachment (Davies 2009), but also are more likely to frequently attend primary care clinics with somatoform symptoms (Taylor 2012). These observations suggest that understanding their behaviour as pathological help-seeking driven by difficulties in relating to caregiving figures may help doctors, especially those working in primary care, to see it in a different way and to adopt certain therapeutic strategies (Adshead 2015).

For example, the finding that frequent attendance is associated with abnormal attachment style suggests that efforts should be made to keep this group of patients seeing the same GP, as there is a greater chance that a trusting relationship will develop than if they constantly see different doctors. Over time a therapeutic relationship can be developed in which underlying psychological and social problems may be revealed. There is also some empirical support (Allen 2006) for approaches that enable patients to receive regular care without it being contingent on symptom production. This might be achieved by (a) recognising that a patient wants support rather than another test and therefore directly addressing pathological health anxiety and worry; and (b) placing explicit boundaries on consulting behaviour by scheduling regular checks for reassurance rather than letting the patient drive the frequency of consultation.

\section{Overlap with factitious disorders}

DSM- 5 suggests that factitious disorders should be considered as a variant of somatoform disorders (Krahn 2008). There is some evidence of overlap in clinical practice, usually at the more severe end of the somatoform spectrum. Fink (1992b) found that a fifth of 'persistent somatisers' had been admitted at least once for factitious illness, and in a study of women with fabricated or induced illness there was substantial co-occurrence of chronic somatoform and factitious disorder in two-thirds of the participants (Bass 2011). Psychiatrists need to be alert to the impact of these illnesses on any dependent children.

\section{Conclusions}

It is important to identify patients with SESD because they often have severe mental illness and/or personality disorder and because of the associated high healthcare costs. Patients can present in a variety of medical settings and recent research suggests that identification and proactive management involving the GP in primary care may be the best way forward. Optimum management requires collaboration and communication between a variety of healthcare workers, but psychiatrists (especially those working in general hospitals) have a responsibility to identify and supervise the management of these patients, as well as to train others in current treatment approaches, while liaising with other health professionals and primary care clinicians. Healthcare commissioners need to be aware of the disability and financial burden posed by this patient group. Future research needs to concentrate on developing services to improve detection and adequate treatment of these patients. Innovative ways of engaging with patients in primary care settings need to be attempted, possibly with trained non-mental health staff.

\section{References}

Aamland A, Malterud K, Werner E (2014) Patients with persistent medically unexplained physical symptoms: a descriptive study from Norwegian general practice. BMC Family Practice, 15: 107.

Abraham H, Anderson C, Lee D (1997) Somatization disorder in Sphincter of Oddi Dysfunction. Psychosomatic Medicine, 59: 553-7.

Adshead G, Guthrie E (2015) The role of attachment in medically unexplained symptoms and long-term illness. BJPsych Advances, 21: 167-74.

Allanson J, Bass C, Wade D (2002) Characteristics of patients with persistent severe disability and medically unexplained neurological symptoms: a psychological enquiry. Journal of Neurology, Neurosurgery and Psychiatry, 73: 307-9.

Allen L, Woolfolk R, Escobar J, et al (2006) Cognitive behavioral therapy for somatisation disorder: a randomized controlled trial. Archives of Internal Medicine, 166: 1512-8.

American Psychiatric Association (1994) Diagnostic and Statistical Manual of Mental Disorders (4th edn) (DSM-IV). APA.

American Psychiatric Association (2013) Diagnostic and Statistical Manual of Mental Disorders, Fifth Edition (DSM-5). APA.

Anderson N, Eplov L, Andersen J, et al (2013) Health care use by patients with somatoform disorders: a register-based follow-up study. Psychosomatics, 54: 32-41

Arnow B (2004) Relationships between childhood maltreatment, adult health and psychiatric outcomes, and medical utilisation. Journal of Clinical Psychiatry, 65 (suppl 12): 10-5.

Barsky A, Orav E, Bates D (2005) Somatization increases medical utilization and costs independent of psychiatric and medical comorbidity. Archives of General Psychiatry, 62: 903-10.

Bass C Murphy M (1991) Somatisation disorder in a British teaching hospital. British Journal of Clinical Medicine, 45: 37-45.

Bass C, Murphy M (1995) Somatoform and personality disorders: syndromal comorbidity and overlapping developmental pathways. Journal of Psychosomatic Research, 39: 403-27.

Bass C, Jones D (2011) Psychopathology of perpetrators of fabricated or induced illness in children: case series. British Journal of Psychiatry, 199: 113-8.

Biskin R, Frankenberg F, Fitzmaurice C, et al (2014) Pain in patients with borderline personality disorder. Personality and Mental Health, 8: 215-7.

Bornstein F, Gold S (2008) Comorbidity of personality disorder and somatisation disorder: a meta-analytic study. Journal of Psychopathology and Behavioural Assessment, 30: 154-61.

Borsini A, Hepgul N, Mondelli V, et al (2014) Childhood stressors in the development of chronic fatigue syndromes: a review of the past 20 years of research. Psychological Medicine, 44: 1809-23.

Bujoreanu S, Randall E, Thomsen K, et al (2014) Characteristics of medically hospitalized pediatric patients with somatoform diagnosis. Hospital Pediatrics, 4: 283-90. 
Burton C, McGorm K, Richardson G, et al (2012a) Healthcare costs incurred by patients repeatedly referred to secondary medical care with medically unexplained symptoms: a cost of illness study. Journal of Psychosomatic Research, 72: 242-7.

Burton C, Weller D, Marsden W, et al (2012b) A primary care symptoms clinic for patients with medically unexplained symptoms: a pilot randomised trial. Journal of Psychosomatic Research, 72: 242-7.

Carroll L (2011) Beliefs and expectations for recovery, coping, and depression in whiplash-associated disorders: lessening the transition to chronicity. Spine, 36: S250-6.

Carson A, Stone J, Hansen C, et al (2015) Somatic symptom count scores do not identify patients with symptoms unexplained by disease: a prospective cohort study of neurology outpatients. Journal of Neurology Neurosurgery and Psychiatry, 86: 295-301.

Cassidy J. Bendix C, Rasmussen C, et al (2011) Is compensation bad for your health? A systematic meta review. Injury, 42: 429-30.

Creed F, Barsky A, Leiknes K (2011) Epidemiology: prevalence, causes and consequences. In Medically Unexplained Symptoms, Somatisation and Bodily Distress (eds F Creed, P Henningsen, P Fink): 1-42. Cambridge University Press.

Davies K, Macfarlane G, McBeth J, et al (2009) Insecure attachment style is associated with chronic widespread pain. Pain, 143: 200-5.

DeVaul R, Faillace L (1980) Surgery-proneness: a review and clinical assessment. Psychosomatics, 21: 295-9.

den Boeft M, van der Wouden J, Rydell-Lexmond T, et al (2014) Identifying patients with medically unexplained physical symptoms in electronic medical records in primary care: a validation study. $B M C$ Family Practice, 5: 109

Dimsdale J, Creed F, Escobar J, et al (2013) Somatic symptom disorder: an important change in DSM. Journal of Psychosomatic Research, 75 : 223-8.

Department of Health (1999) A National Service Framework for Mental Health: Modern Standards and Service Models. TSO (The Stationery Office).

Dykes S, Smilgin-Humphries S, Bass C (2001) Chronic idiopathic constipation: a psychological enquiry. European Journal of Gastroentreology and Hepatology, 13: 39-44.

Fiddler M, Jackson J, Kapur N, et al (2004) Childhood adversity and frequent medical consultations. General Hospital Psychiatry, 26: 367-77.

Fink $P$ (1992a) The use of hospitalizations by persistent somatizing patients. Psychological Medicine, 22: 173-80.

Fink P (1992b) Physical complaints and symptoms of somatizing patients. Journal of Psychosomatic Research, 36: 125-36.

Fossati A, Maffei C, Bagnato M, et al (1998) Criterion validity of the Personality Diagnostic Questionnaire-4+ (PDQ-4+) in a mixed psychiatric sample. Journal of Personality Disorders, 12: 172-8.

Frankenburg F, Zanarini M (2004) The association between borderline personality disorder and chronic medical illnesses, poor health-related lifestyle choices, and costly forms of health care utilization. Journal of Clinical Psychiatry, 65: 1660-5.

Frohlich C, Jacobi F, Wittchen H (2006) DSM-IV pain disorder in the general population: an exploration of the structure and threshold of medically unexplained pain symptoms. European Archives of Psychiatry and Clinical Neuroscience, 256: 187-96.

Frostholm L, Petrie K, Ornbol E, et al (2014) Are illness beliefs related to future healthcare expenditure in patients with somatoform disorders? Psychological Medicine, 44: 2903-11.

Frostholm L, Ornbol E, Fink P (2015) Physical symptom attributions: a defining characteristic of somatoform disorders? General Hospital Psychiatry, 37: 7-52

Gibbon M, Spitzer RL, First MB (1997) User's Guide for the Structured Clinical Interview for DSM-IV Axis II Personality Disorders: SCID-II. American Psychiatric Association.

Hoeritzauer I, Stone J, Fowler C, et al (2015) Fowler's syndrome of urinary retention: a retrospective study of comorbidity. Neurourology and Urodynamics, 10 April, doi: 10.1002/nau.22758 [Epub ahead of print].
Holliday K, McBeth J (2011) Recent advances in the understanding of genetic susceptibility to chronic pain and somatic symptoms. Current Rheumatology Reports, 13: 521-7.

Improving Access to Psychological Therapies (2015) Medically unexplained symptoms. National Health Service (http://www.iapt.nhs. uk/Itcmus/medically-unexplained-symptoms). Accessed 25 May 2015.

Jackson J, Passamonti M (2005) The outcomes among patients in primary care with a physical symptom at 5 years. Journal of General Internal Medicine, 20: 1032-37.

Jackson J, Kroenke K (2008) Prevalence, impact, and prognosis of multisomatoform disorder in primary care: a 5-year follow-up study. Psychosomatic Medicine, 70: 430-4.

Kanaan R, Lepine J, Wessely S (2007) The association or otherwise of the functional somatic syndromes. Psychosomatic Medicine, 69: 855-9.

Kapur N, Hunt I, MacFarlane G, et al (2004) Childhood experience and health care use in adulthood. Nested case-control study. British Journal of Psychiatry, 185: 134-9.

Kinder A, Jorsh M, Johnston K, et al (2006) Somatization disorder: a defensive waste of NHS resources. Rheumatology, 43: 72-4.

Konnopka A, Kaufman C, Konig H, et al (2013) Association of costs with somatic symptom severity in patients with medically unexplained symptoms. Journal of Psychosomatic Research, 75: 370-5.

Kouyanou K, Pither C, Wessely S (1997) latrogenic factors and chronic pain. Psychosomatic Medicine, 59: 597-604.

Krahn L, Bostwick J, Stonnington C (2008) Looking toward DSM-V: should factitious disorder become a subtype of somatoform disorder? Psychosomatics, 49: 277-82.

Krishnan V, Sood M, Chadda R (2013) Caregiver burden and disability in somatisation disorder. Journal of Psychosomatic Research, 75: 376-80.

Kroenke K, Spitzer R, Williams J (2002) The PHQ-15: validity of a new measure for evaluating the severity of somatic symptoms. Psychosomatic Medicine, 64: 258-66.

Kushwaha V, Sinha Deb K, Chadda R, et al (2014) A study of disability and its correlates in somatisation disorder. Asian Journal of Psychiatry, 8: $56-8$.

Lee S, Creed F, Ma Y, et al (2015) Somatic symptom burden and health anxiety in the population and their correlates. Journal of Psychosomatic Research, 78: 1-6.

Loranger AW, Jance A, Sartorius N (eds) (1997) Assessment and Diagnosis of Personality Disorders: The ICD-IO International Personality Disorder Examination (IPDE). Cambridge University Press.

olde Hartman T, Borghuis M, Lucassen P, et al (2009) Medically unexplained symptoms, somatisation disorder and hypochondriasis: course and prognosis. A systematic review. Journal of Psychosomatic Research, 66: 363-77.

Paris R (2007) Why psychiatrists are reluctant to diagnose borderline personality disorder. Psychiatry, 4: 35-9

Petrie K, Weinman J (2012) Patients' perceptions of their illness: the dynamo of volition in health care. Current Directions in Psychological Science, 21: 60-5.

Rask M, Rosendal M, Fenger-Gron M, et al (2015) Sick leave and work disability in primary care patients with recent-onset multiple medically unexplained symptoms and persistent somatoform disorders: a 10-year follow-up of the FIP study. General Hospital Psychiatry, 37: 53-9.

Reid S, Wessely S, Crayford T, et al (2002) Frequent attenders with medically unexplained symptoms: service use and costs in secondary care. British Journal of Psychiatry, 180: 248-53.

Riebel K, Egloff B, Witthoft M (2013) The implicit health-related selfconcept in somatic symptom disorders. Journal of Behaviour Therapy and Experimental Psychiatry, 44: 335-42

Rief W, Nanke A, Emmerich J, et al (2004) Causal illness attributions in somatoform disorders. Associations with comorbidity and illness behaviour. Journal of Psychosomatic Research, 57: 367-71.

Rief W, Broadbent E (2007) Explaining medically unexplained symptomsmodels and mechanisms. Clinical Psychology Review, 27: 821-41.

\section{MCO answers}

1 a 2 d $\quad 3$ c $\quad 4$ b 5 e 
Rief W, Mewes R, Martin A, et al (2010) Are psychological features useful in classifying patients with somatic symptoms? Psychosomatic Medicine, 72: 648-55.

Robinson P (2014) Severe and enduring eating disorders: recognition and management. Advances in Psychiatric Treatment, 20: 392-401.

Röhricht F, Elanjithara T (2014) Management of medically unexplained symptoms: outcomes of a specialist liaison clinic. Psychiatric Bulletin, 38: $102-7$

Rosendal M, Blankenstein A, Morriss R, et al (2013) Enhanced care by generalists for functional somatic symptoms and disorders in primary care. Cochrane Database of Systematic Reviews, 10: CD008142.

Schrag A, Brown R, Trimble M (2004) Reliability of self-reported diagnoses in patients with neurologically unexplainrd neurological symptoms. Journal of Neurology Neurosurgery and Psychiatry, 75: 608-11

Sharpe M, Stone J, Hibberd C, et al (2010) Neurology outpatients with symptoms unexplained by disease: illness beliefs and financial benefits predict one-year outcome. Psychological Medicine, 40: 689-98.

Sharpe M (2013) Somatic symptoms: beyond 'medically unexplained'. British Journal of Psychiatry, 203: 320-1.

Shraim M, Blagojevic-Bucknell M, Mallen C, et al (2014) The association between GP consultations for non-specific physical symptoms in children and parents: a case-control study. PLoS One, 9: e108039.

Steinbrecher N, Hiller W (2011a) Course and prediction of somatoform disorder and medically unexplained symptoms in primary care. General Hospital Psychiatry, 33: 318-26.

Steinbrecher N, Koerber S, Frieser D, et al (2011b) The prevalence of medically unexplained symptoms in primary care. Psychosomatics, 52 : 263-71

Stone J (2014) Psychotherapy for severe somatoform disorder: problems with missing studies. British Journal of Psychiatry, 204: 243-4

Taylor R, Marshall T, Mann A, et al (2012) Insecure attachment and frequent attendance in primary care: a longitudinal cohort study of medically unexplained symptom presentations in ten UK general practices. Psychological Medicine, 42: 855-64.

Thomsen K, Randall E, Ibeziako P, et al (2014) Somatoform disorders and trauma in medically admitted children, adolescents, and young adults: prevalence rates and psychosocial characteristics. Psychosomatics, 55 : $630-9$

Tomenson B, Essau C, Jacobi F et al (2013) Total somatic symptom score as a predictor of health outcome in somatic symptom disorders. British Journal of Psychiatry, 203: 373-80.
Tyrer P, Fowler-Dixon R, Ferguson B, et al (1990) A plea for the diagnosis of hypochondriacal personality disorder. Journal of Psychosomatic Research, 34: 637-42.

Tyrer P, Seivewright N, Seivewright H (1999) Long term outcome of hypochondriacal personality diasorder. Journal of Psychosomatic Research, 46: 177-85

Tyrer P, Reed G, Crawford M (2015a) Classification, assessment, prevalence, and effect of personality disorder. Lancet, 385: 717-26.

Tyrer H, Tyrer P, Lisseman-Stones $\mathrm{Y}$, et al (2015b) Therapist differences in a randomised trial of the outcome of cognitive behaviour therapy for health anxiety in medical patients. International Journal of Nursing Studies, 52: 686-94.

Vakili S, Alam T, Sollinger H (2014) Loin pain haematuria syndrome. American Journal of Kidney Disease, 64: 460-72

van der Feltz-Cornelis C, Swinkels J (2012) Presentation of the Multidisciplinary Guideline Medically Unexplained Physical Symptoms (MUPS) and Somatoform Disorder in the Netherlands: disease management according to risk profiles. Journal of Psychosomatic Research, 72: 168-9. van Dessel N, den Boeft M, van der Wouden J, et al (2014) Nonpharmacological interventions for somatoform disorders and medically unexplained symptoms in adults. Cochrane Database of Systematic Reviews, 11: CD011142.

van Ravesteijn H, Wittkampf K, Lucassen P, et al (2009) Detecting somatoform disorders in primary care with the PHQ-15. Annals of Family Medicine, 7: 232-8.

Voigt K, Wollburg E, Weinmann N, et al (2013) Predictive validity and clinical utility of DSM-5 Somatic Symptom Disorder: prospective 1-year follow-up study. Journal of Psychosomatic Research, 75: 358-61.

Vranceanu A, Barsky A, Ring D (2011) Less specific arm illnesses. Journal of Hand Therapy, 24: 118-22.

Warren J, Langenberg P, Clauw D (2013) The number of existing functional somatic syndromes (FSSs) is an important risk factor for new, different FSSs. Journal of Psychosomatic Research, 74: 12-7.

Warren J, Clauew D, Wesselman U, et al (2014) Functional somatic syndromes as risk factors for hysterectomy in early bladder pain syndrome/ interstitial cystitis. Journal of Psychosomatic Research, 77: 363-67.

Wolfe F, Brahler E, Hinz A, et al (2013) Fibromyalgia prevalence, somatic symptom reporting, and the dimensionality of polysymptomatic distress: results from a survey of the general population. Arthritis Care Research, 65: 777-85.

World Health Organization (1992) ICD-10: The ICD-10 Classification of Mental and Behavioural Disorders: Clinical Descriptions and Diagnostic Guidelines. WHO

\begin{tabular}{|c|c|c|}
\hline $\begin{array}{l}\text { MCOs } \\
\text { Select the single best option for each question stem }\end{array}$ & d somatic symptoms that are distressing and & $\begin{array}{l}\text { c number of primary care consultations } \\
d \text { involvement of family members }\end{array}$ \\
\hline $\begin{array}{l}1 \text { The prevalence of SESD in the general } \\
\text { population is: }\end{array}$ & & \\
\hline $\begin{array}{l}\text { a } 5-7 \% \\
\text { b } 20 \% \\
\text { c } 2 \% \\
\text { d } 50 \% \\
\text { e } 0.1 \%\end{array}$ & $\begin{array}{l}3 \text { Clinical features of SESD may not include: } \\
\text { a a chronic medical disorder } \\
\text { b a personality disorder } \\
\text { c lack of treatability } \\
\text { d abnormal illness behaviour } \\
\text { e abnormalities in the perception and reporting of }\end{array}$ & $\begin{array}{l}5 \text { Knowledge of attachment theory may be } \\
\text { helpful in management because: } \\
\text { a of the presence of personality disorder } \\
\text { b sociopathic tendencies are common } \\
\text { c of problems with impulse control } \\
\text { d depersonalisation is common }\end{array}$ \\
\hline $\begin{array}{l}2 \text { Patients with SESD satisfy the following } \\
\text { criteria: }\end{array}$ & physical symptoms. & $\begin{array}{l}\text { e the consulting behaviour can be seen as a form } \\
\text { of pathological help-seeking. }\end{array}$ \\
\hline $\begin{array}{l}\text { a drug misuse } \\
\text { b personality disorder } \\
\text { c repeated self-harm }\end{array}$ & $\begin{array}{l}4 \text { Persistence in SESD is predicted by: } \\
\text { a absence of personality disorder } \\
\text { b number of physical symptoms }\end{array}$ & \\
\hline
\end{tabular}

